Article

\title{
Improvement and Application of Key Pasture Theory for the Evaluation of Forage-Livestock Balance in the Seasonal Grazing Regions of China's Alpine Desert Grasslands
}

\author{
Hui Liu $®$, Xiaoyu Song *, Lin Qin $₫$, Wang Wen, Xiaodi Liu, Zhiqiang Hu and Yu Liu \\ State Key Laboratory of Eco-Hydraulics in Northwest Arid Region of China, Xi'an University of Technology, \\ Xi'an 710048, China; hui_369@126.com (H.L.); qinlin1414@163.com (L.Q.); lqwenwang@126.com (W.W.); \\ 1xd2457191xd@163.com (X.L.); huzhiqiang233@163.com (Z.H.); yuyu_xaut@163.com (Y.L.) \\ * Correspondence: songxy@xaut.edu.cn; Tel.: +86-135-7259-3963
}

Received: 5 July 2020; Accepted: 10 August 2020; Published: 21 August 2020

\begin{abstract}
The calculation of theoretical carrying capacity (TCC) is one of the most fundamental tasks for the evaluation of the forage-livestock balance on grassland pastures. At present, the main methods for calculating TCC are the traditional theory (TT) and key pasture theory (KPT), but they both have obvious limitations in practical applications for the seasonal grazing regions in the alpine desert grasslands of China. In this study, the pastures in Wulan County (PWC) were selected as the research area. The unique features of the research area as well as the faulty applications of TT and KPT were fully analyzed, and then a new method named dynamic key pasture theory (DKPT) was established for calculating TCC by improving KPT with the introduction of the two dynamic factors of the livestock slaughter rate $(\alpha)$ and coefficient of grassland productivity $(\beta)$. TT, KPT and DKPT were respectively used to calculate the TCC of the PWC under different precipitation scenarios. The forage-livestock balance in the PWC determined using DKPT was assessed by the forage-livestock balance index (FLBI). The results showed that the natural processes of grassland supply and livestock demand were significantly imbalanced in time and space and formed a dynamic cycle with four subprocesses, which was the supporting basis of DKPT; DKPT effectively improved the rationality of TCC and offered greater guidance for the evaluation of the forage-livestock balance in the seasonal grazing regions of China's alpine desert grasslands. In the PWC, the TCCs of different pastures calculated by DKPT were clearly different from those calculated by TT and KPT; the areas of the pastures divided were extremely imbalanced, with a huge surplus of more than 50\% in cool-season pastures; in the representative year of 2016, the pastures in the Xisai Basin were underloaded (FLBI $=-35.19 \%$ ) on the whole, while the pastures in the Chaka Basin were overloaded (FLBI $=24.34 \%$ ).
\end{abstract}

Keywords: Wulan County; seasonal grazing region; supply-demand relationship; key pasture theory; theoretical carrying capacity; forage-livestock balance

\section{Introduction}

Grasslands are among the major ecosystems in the world, providing various ecosystem and social service functions [1-4]. Animal husbandry is the mainstay of economic and social development in grassland regions, and maintaining the forage-livestock balance is crucial to the sustainable development of grassland animal husbandry [5-11]. The forage-livestock balance means that, in order to maintain the beneficial cycles of the grassland ecosystem, the total amount of forage provided by the grasslands, as well as other sources, should be in dynamic balance with the amount of forage needed to raise the livestock $[12,13]$. Thus, the calculation of the theoretical carrying capacity (TCC) of the 
pasture to determine the appropriate grazing intensity is one of the most fundamental tasks for the evaluation of the forage-livestock balance, with the accuracy of the TCC estimate directly affecting the reliability of the results and the sustainability of the system.

In terms of the forage-livestock balance, most previous studies have focused mainly on estimating the grassland productivity and edible forage yield of the pastures, from which the TCC of the pastures could be obtained using the traditional theory (TT) to estimate the forage-livestock balance [14-18]. For the seasonal grazing regions in alpine desert grasslands in China, using TT to calculate TCC largely ignores the influence of factors such as spatial-temporal differentiation in grassland productivity and variations in livestock numbers, and it fails to fully consider the natural relationship between grassland supply and livestock demand. The estimate of the forage-livestock balance based on TT is nearly static $[19,20]$, providing little guidance of significance for the operation and management of animal husbandry and the sustainability of grassland ecosystems, and even proved to be counterproductive, in fact.

To date, there have been few studies on the theory of TCC calculation. One attempt was key pasture theory (KPT), proposed by Quangong Chen [21] in 2005, which is conducive to the sustainable development of animal husbandry and seasonal pastures. KPT uses TT to calculate the carrying capacity of each seasonal pasture, and the seasonal pasture in the grazing system with the lowest carrying capacity is defined as the key pasture, which, in turn, determines the maximum livestock carrying capacity of the entire grassland grazing system throughout the whole year. KPT is a very useful measure for the restoration and conservation of grassland ecosystems, but there are still some problems in its application. For example, KPT still belongs to the static balance theories because it is based on TT and fails to eliminate the shortcomings of TT; KPT further amplifies the imbalance of grassland supply and livestock demand, which can easily result in insufficient forage utilization and, hence, cause a waste of grassland resources in nonkey pastures. This study further analyzed and optimized TT and KPT with a view to perfecting theoretical research on the calculation of TCC and generating a more effective measure of the forage-livestock balance in the seasonal pastoral regions in the alpine desert grasslands of China.

Wulan County [22], located in Qinghai Province, China, is rich in grassland resources, with natural grasslands accounting for about $60 \%$ of the total land area of the county, and it is representative of the seasonal grazing regions in the alpine desert grasslands of China. Animal husbandry has long been the economic mainstay of the region. Since 1956, managers of pastures in Wulan County (PWC) have implemented seasonal grazing during the warm and cool seasons. Influenced by the Qaidam Basin Desert, the ecological environment of the PWC is extremely fragile. Therefore, it is vital to carry out research on TCC calculation in the region in order to achieve a dynamic evaluation of the forage-livestock balance in the PWC to promote the sustainable development of the regional social economy while protecting its environment and associated ecologies.

\section{Materials and Methods}

\subsection{Profile of Wulan County}

The research was carried out on the seasonal pastures of Wulan County, Qinghai Province, east of the Qaidam Basin in China $\left(97^{\circ} 01^{\prime} \mathrm{E}-99^{\circ} 27^{\prime} \mathrm{E}, 36^{\circ} 19^{\prime} \mathrm{N}-37^{\circ} 20^{\prime} \mathrm{N}\right.$ ) (Figure 1). The average altitude is about $4000 \mathrm{~m}$, average annual precipitation is $187.5 \mathrm{~mm}$, the average annual evaporation from water surfaces is $2000-3000 \mathrm{~mm}$ and the average annual temperature is $1.6-3.3^{\circ} \mathrm{C}$. The region has a short frost-free period, during which there is sufficient sunshine, a large temperature difference between day and night and rain and heat over the same period, and belongs to the Alpine continental climate. Wulan County is composed of the Xisai Basin and the Chaka Basin. The total area of natural grasslands in the study area is 1,096,000 ha, of which the available grasslands cover 490,700 ha; in addition, there are a further 1540 ha of artificial grasslands, which are fenced off from the rest of the land and used for artificial forage grass planting for supplementary forage production. The year 2016 was selected as the 
representative year, taking into consideration the completeness of the data in the study area, and it was a wet year, with a rainfall of $274.6 \mathrm{~mm}$.

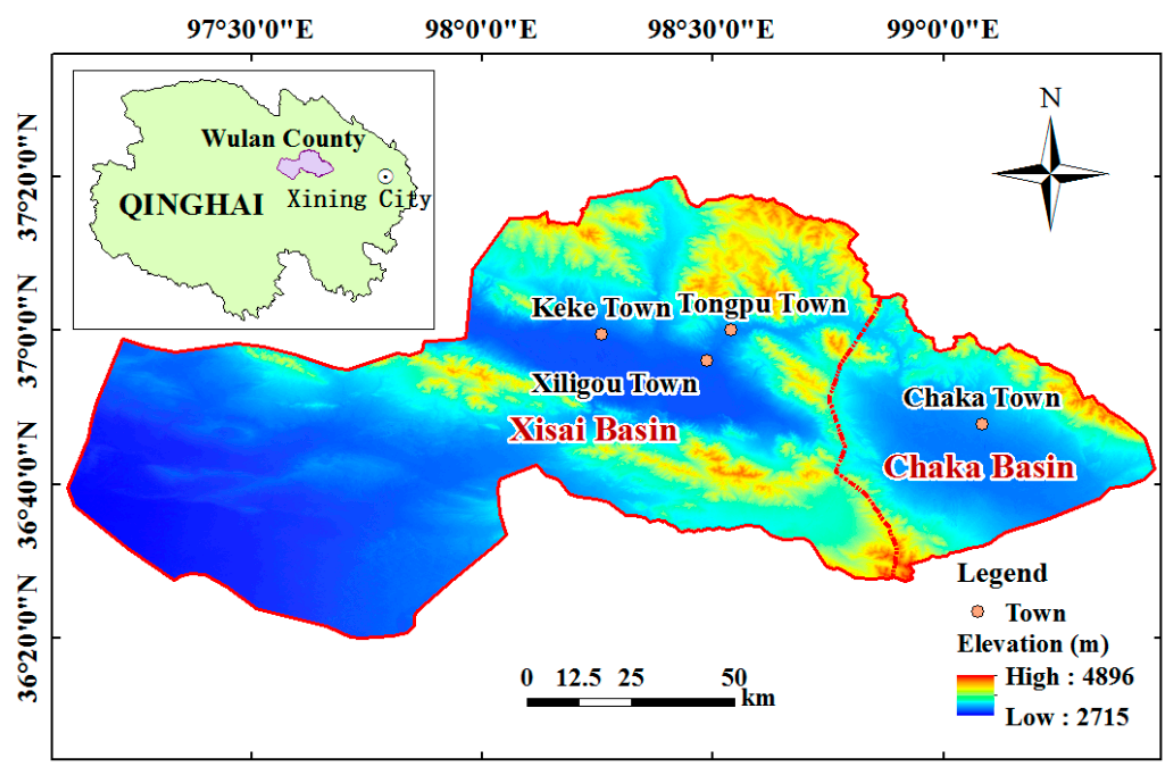

Figure 1. Geographic location of Wulan County.

\subsection{Analysis of the Natural Relationship between Forage Production and Livestock Demand}

According to the Local Chronicles of Wulan County [22], the grassland growth period in the PWC runs from the beginning of April, when the grass starts to turn green, to the end of October, when the grass stops growing, with a growth period of about 206 days. Managers of the PWC implement seasonal grazing in the cool (winter and spring) and warm (summer and autumn) seasons. The grazing period for the cool-season pasture is from late November to the end of June of the following year, and the grazing period is about 221 days. The grazing period for the warm-season pasture is from the beginning of July to the middle of November, and the grazing period is about 144 days. Artificial grasslands are used as a supplement for local livestock in winter and spring.

The forage demand of the livestock depends mainly on the changes in actual livestock numbers, which are mainly reflected in the production patterns of animal husbandry in the PWC. In the operation and management cycle of animal husbandry, changes in actual livestock numbers are controlled by two production nodes, namely, lambing (January to April) and slaughter (September to October), in which the whole year is divided into two stages: stage I, from May to October, when actual livestock numbers reach their maximum value due to the completion of lambing in April, which is equal to the stocking number at midyear in June; and stage II, from November to April of the following year, when actual livestock numbers reach their minimum value due to the completion of livestock slaughter in October, which is equal to the stocking number at year's end in December.

Extracted from relevant research studies [23-25] and statistical data, edible forage yields converted to standard hay from the natural and artificial grasslands in the study area in the representative year are shown in Table 1 . The coefficients of grassland productivity, $\beta$, under different precipitation scenarios are $1.13,1.00$ and 0.87 in wet, normal and dry years, respectively. The actual livestock numbers at midyear and year's end in the study area in the representative year are shown in Table 2. In the calculation of the forage-livestock balance, livestock of different types, sizes and ages are usually converted to "standard livestock". In China, the "standard livestock" is the sheep unit, an adult sheep weighing $45 \mathrm{~kg}$ with daily consumption of $1.8 \mathrm{~kg}$ of standard hay. From the statistics on animal husbandry in Wulan County from 2008 to 2016, it can be shown that $\alpha$, the average annual slaughter rate of livestock, is $45.5 \%$. 
Table 1. Edible forage yield of the pastures in Wulan County in $2016\left(10^{4} \mathrm{~kg}\right)$.

\begin{tabular}{cccc}
\hline District & Warm-Season Pasture & Cool-Season Pasture & Artificial Grassland \\
\hline Xisai Basin & 20,321 & 29,508 & 1218 \\
Chaka Basin & 4018 & 5879 & 438 \\
\hline
\end{tabular}

Table 2. Actual livestock numbers at midyear and year's end in the pastures in Wulan County in 2016 $\left(10^{4}\right.$ sheep units).

\begin{tabular}{ccc}
\hline District & Midyear & Year's End \\
\hline Xisai Basin & 47.38 & 38.70 \\
Chaka Basin & 18.77 & 14.17 \\
\hline
\end{tabular}

Through analysis of the data above, the relationship between grassland productivity and livestock demand was investigated and is shown in Figure 2. In the PWC, edible forage yield supplied by natural grasslands was concentrated in the period from May to October, reaching a peak in July, with the natural forage production from the cool-season pastures generally being higher than that from the warm-season pastures. The natural forage demand of the livestock changes with livestock numbers, forming a cycle within the livestock husbandry year that should ideally match the variation in livestock numbers over the two stages. The main goal of stage I is "livestock feeding and earning". In stage I, forage resources are abundant, the stocking number is high, forage demand is high and herders obtain economic benefits through livestock fattening and wool production. The main goal of stage II is "livestock protection and overwintering". In stage II, livestock numbers are reduced to the stocking level at year's end as a result of slaughter, and the natural forage demand decreases correspondingly, with the herders needing to overcome difficulties such as a shortage of forage and the need for the livestock to withstand the harsh environmental conditions in the cool season in order to maintain a certain number of livestock to ensure successful breeding and, hence, restoration of livestock numbers in the following year. Over the whole year, however, the natural variations in forage supply and livestock demand exhibit a significant imbalance over time. Seasonal pastures, supplemented by artificial grasslands, can effectively alleviate the imbalance between natural supply and demand. Moreover, the seasonal grazing cycle and the natural forage demand cycle of the livestock intersect, forming a dynamic cycle with four subprocesses of natural supply and demand throughout the year. The natural relationship between forage supply and livestock demand is complex (Figure 2), so it is necessary to further refine the management of the forage-livestock balance in order to achieve a "real" dynamic balance between forage and livestock in alpine desert seasonal pastures.

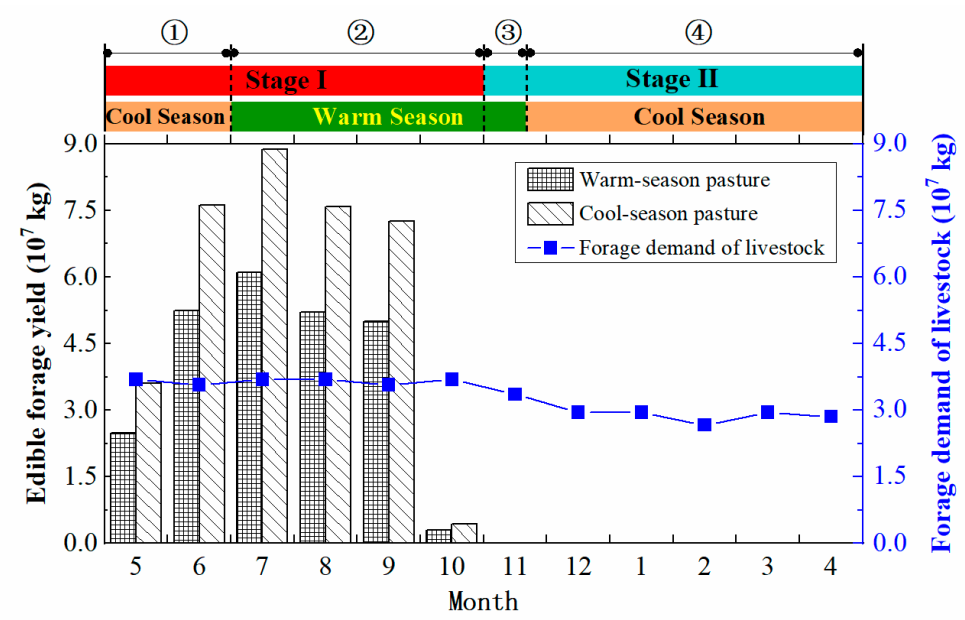

Figure 2. Relationship between grassland forage supply and livestock demand in the pastures in Wulan County. 


\subsection{Methods}

TCC is the main measure of livestock numbers that can be carried by a certain area of grassland within a certain period under the premise of proper grazing (or mowing) intensity and, at the same time, meeting the livestock's needs for normal growth, reproduction and productivity. The actual carrying capacity (ACC) is the actual livestock number carried by a certain area of grassland within a certain period. The state of the forage-livestock balance on pastures was evaluated by comprehensively comparing the TCC and ACC, using TT and KPT to calculate the TCC and assessing dynamic key pasture theory (DKPT), a new method (based on KPT) for calculating TCC.

\subsubsection{Traditional Theory (TT)}

TT-based TCC [18] is based on grassland productivity and standard livestock daily forage consumption. The PWC involve seasonal grazing in both the cool and warm seasons. In the warm season, forage demand by the livestock is supplied by warm-season pastures, whereas in the cool season, it is provided by cool-season pastures, supplemented by artificial grasslands. In this way, the TCC of seasonal pastures over different periods is calculated according to the following equations:

$$
\begin{gathered}
A_{w}=\frac{F_{w}}{I \times D_{w}} \\
A_{c}=\frac{F_{c}+F_{h}}{I \times D_{c}} \\
A_{y}=\frac{A_{w} \times D_{w}}{365}+\frac{A_{c} \times D_{c}}{365}
\end{gathered}
$$

where $A_{w}, A_{c}$ and $A_{y}$, respectively, represent the TCC in the warm season, in the cool season and year-round (sheep units); $F_{w}, F_{c}$ and $F_{h}$, respectively, represent the edible forage yield in terms of standard hay on warm-season pastures, cool-season pastures and artificial grasslands $(\mathrm{kg})$; I represents the daily forage consumption of domestic animals by a standard sheep unit (approximately $1.8 \mathrm{~kg} /$ day); $D_{w}$ and $D_{c}$, respectively, represent the number of grazing days in the warm and cool seasons (day), and the corresponding values in the PWC are 221 days and 144 days, respectively.

According to the National Agricultural Industry Standard [18], evaluation of the forage-livestock balance involves comparison and analysis of the TCC and ACC values of the seasonal pastures. The ACC in the warm-season pasture is the stocking number at midyear, and the ACC in the cool-season pasture is the stocking number at year's end, whereas the ACC of the entire grassland grazing system all year round is calculated using the following equation:

$$
L_{y}=\frac{L_{w} \times D_{w}}{365}+\frac{L_{c} \times D_{c}}{365}
$$

where $L_{w}, L_{c}$ and $L_{y}$ represent the ACC in the warm season, in the cool season and year-round (sheep units), respectively.

The state of the forage-livestock balance in the seasonal pasture is measured by the forage-livestock balance index (FLBI) [26,27], which is calculated according to Equation (5) and is divided into six levels based on the FLBI values (Table 3), representing extreme overload, serious overload, overload, marginal overload, balance and underload, respectively.

$$
\text { FLBI }=\frac{L_{*}-A_{*}}{A_{*}} \times 100 \%
$$

where FLBI is the forage-livestock balance index, $A_{*}$ is the TCC (sheep units) and $L_{*}$ is the ACC (sheep units). 
Table 3. Classification of the forage-livestock balance index in pastures.

\begin{tabular}{cc}
\hline Level & Range of Index \\
\hline Extreme overload & $150 \% \leq$ FLBI \\
Serious overload & $80 \% \leq$ FLBI $<150 \%$ \\
Overload & $20 \% \leq$ FLBI $<80 \%$ \\
Marginal overload & $0 \leq$ FLBI $<20 \%$ \\
Balance & $-20 \% \leq$ FLBI $<0$ \\
Underload & FLBI $<-20 \%$ \\
\hline
\end{tabular}

\subsubsection{Key Pasture Theory (KPT)}

KPT [21] states that, in the seasonal grazing system, the carrying capacities of different seasonal pastures are obviously different from each other and are mainly affected by the features of the seasonal pastures, such as area, grassland type, grass yield, grassland utilization rate, herd structure, grazing days and so on, with the pasture with the lowest carrying capacity being defined as the key pasture in the entire seasonal grazing system. The key pasture determines the maximum carrying capacity of the entire seasonal grazing system; in other words, the carrying capacity of the key pasture is the TCC, the limiting index for the entire seasonal grazing system in an animal husbandry year. In terms of KPT, the TCC of a seasonal grassland with two seasonal pastures (warm- and cool-season) could be calculated by Equation (6) and then combined with the FLBI (Equation (5) and Table 3) to carry out the calculation of the forage-livestock balance in the PWC.

$$
A_{k}=\min \left\{A_{w}, A_{c}\right\}
$$

where $A_{k}$ is the TCC of the entire seasonal grazing system in an animal husbandry year calculated by KPT (sheep units).

\subsubsection{Dynamic Key Pasture Theory (DKPT)}

The two theories above, TT and KPT, divide the pasture into two seasonal pastures (warm and (ool), for which TCC values are calculated independently. The two calculation processes and the results are independent of one another, without fully taking into consideration the internal link caused by the change in livestock numbers as well as the natural relationship between grassland supply and livestock demand in an animal husbandry year. The results of the forage-livestock balance based on TT or KPT, therefore, are near-static. Hence, a new theory, DKPT, was proposed.

Based on Figure 2 and the analysis presented above, the dynamic cycle of grassland supply and livestock demand in the PWC within an animal husbandry year was divided into four subprocesses (Table 4) representing the natural relationship between grassland supply and livestock demand. $\alpha$ and $\beta$ are the dynamic parameters reflecting the variations in livestock numbers and the interannual changes in grassland productivity, respectively. DKPT was developed using the following equations to improve KPT by taking into account the natural relationship between forage supply and livestock numbers, $\alpha, \beta$ and so on.

Table 4. Dynamic cycle division of grassland supply and livestock demand in seasonal pastures.

\begin{tabular}{cccc}
\hline Subprocess & Stocking Number & Pasture Type & Grazing Days \\
\hline (1) & $a$ & Cool-season & 61 \\
$(2)$ & $a$ & Warm-season & 123 \\
$(3)$ & $b$ & Warm-season & 21 \\
(4) & $b$ & Cool-season & 160 \\
\hline
\end{tabular}

$a$ and $b$ represent the stocking number at midyear and year's end (sheep units), respectively. 
The relationship between $a$ and $b$ is

$$
b=(1-\alpha) \times a
$$

and for warm-season pastures (subprocesses (2) and (3)

$$
\beta \times F_{w}=a \times D_{D K, 2} \times I+b \times D_{D K, 3} \times I
$$

Then, Equations (7) and (8) can jointly derive $a$, the stocking number at midyear based on the carrying capacity of the warm-season pasture, defined as $a^{\prime}$ and expressed as

$$
a^{\prime}=\frac{\beta \times F_{w}}{I \times\left(D_{D K, 2}+D_{D K, 3}-\alpha \times D_{D K, 3}\right.} .
$$

For cool-season pastures (subprocesses (1) and (4))

$$
\beta \times F_{c}+F_{h}=a \times D_{D K, 1} \times I+b \times D_{D K, 4} \times I,
$$

Then, Equations (7) and (10) can also jointly derive $a$, the stocking number at midyear, but based on the carrying capacity of the cool-season pasture, defined as $a^{\prime \prime}$ and expressed as

$$
a^{\prime \prime}=\frac{\beta \times F_{c}+F_{h}}{I \times\left(D_{D K, 1}+D_{D K, 4}-\alpha \times D_{D K, 4}\right.}
$$

According to the basic principles of key pasture theory, the TCCs of warm-season pastures $\left(A_{D K, w}\right)$, cool-season pastures $\left(A_{D K, c}\right)$ and year-round in seasonal pastures $\left(A_{D K, y}\right)$ are as follows:

$$
\begin{gathered}
A_{D K, w}=\min \left\{a^{\prime}, a^{\prime \prime}\right\} \\
A_{D K, c}=(1-\alpha) A_{D K, w} \\
A_{D K, y}=\frac{A_{D K, w} \times D_{D K, 1}}{365}+\frac{A_{D K, w} \times D_{D K, 2}}{365}+\frac{A_{D K, c} \times D_{D K, 3}}{365}+\frac{A_{D K, c} \times D_{D K, 4}}{365}
\end{gathered}
$$

If $A_{D K, w}=a^{\prime}$, the key pasture is the warm-season pasture, whereas, if $A_{D K, w}=a^{\prime \prime}$, the key pasture is the cool-season pasture.

From Equation (7) to Equation (14), $a$ and $b$, respectively, represent the stocking numbers at midyear and year's end (sheep units); $a^{\prime}$ and $a^{\prime \prime}$ are the stocking numbers at midyear based on the carrying capacity of warm-season pastures and cool-season pastures (sheep units), respectively. $A_{D K, w}$, $A_{D K, c}$ and $A_{D K, y}$ represent the TCC in warm-season pastures, in cool-season pastures and year-round (sheep units), respectively; $D_{D K, 1}, D_{D K, 2}, D_{D K, 3}$ and $D_{D K, 4}$ are the numbers of grazing days in each subprocess (days), and $D_{D K, 1}+D_{D K, 2}+D_{D K, 3}+D_{D K, 4}=365$ (days); $\alpha$ is the slaughter rate, of which the value is calculated based on the average annual value of slaughter rates on the seasonal pastures; and $\beta$ is the coefficient of grassland productivity under different precipitation scenarios of wet, normal and dry years, equaling $1.13,1.00$ and 0.87 , respectively.

It can be seen that the TCC of a seasonal grazing region is mainly controlled by the areas of warm-season pastures, cool-season pastures and artificial pastures; regional precipitation; and livestock slaughter rates, all of which are also the key factors by which DKPT achieves the dynamic regulation of forage-livestock balance in seasonal grazing regions. 


\section{Results}

\subsection{TCCs of Seasonal Pastoral Regions under Different Precipitation Scenarios}

The TCCs of the PWC were calculated using the three methods, namely, TT, KPT and DKPT, under the different precipitation scenarios of wet, normal and dry years (Table 5). In the wet year, the TCC increased by about 30\% compared with the value in the dry year, averaged over the three calculation methods, indicating that regional precipitation had a significant impact on the grassland productivity and TCC for the pasture regions [28,29]. The results from the TT method showed that the TCC in the warm-season pasture was slightly higher than the one in the cool-season pasture in the Xisai Basin, whereas the results in the Chaka Basin were the opposite, with the TCCs in the warm season, the cool season and the whole year being very close to one another, the maximum deviation being less than $5 \%$ (Table 5). The results from the KPT method showed that the key pasture in the Xisai Basin was the cool-season pasture, while the key pasture in the Chaka Basin was the warm-season pasture, with the carrying capacities of the key pastures being the TCCs of the seasonal pasture region over the whole year. However, the differences in carrying capacities between the key pasture and the nonkey pasture in the two basins were, again, less than 5\%, similar to the findings from the TT method. The results from the DKPT method showed that $a^{\prime \prime}$ was about 1.4 times the value of $a^{\prime}$ in the two basins under all the different precipitation scenarios. As a consequence, the key pasture in each of the two basins, calculated by the DKPT method, was the warm-season pasture, a finding that was different from the results obtained using the KPT method. In the two basins, the TCCs of the cool-season pastures deduced through the DKPT method from Equation (13) were only about $42 \%$ of the ACCs. Compared with the results from the TT and KPT methods, the TCCs of the warm-season pastures calculated by the DKPT method were 7.07-8.71\% higher, whereas the TCCs of the cool-season pastures decreased by nearly half (40.78-44.23\%); as a consequence, the TCCs of the whole year calculated by the DKPT method decreased by 15.83-19.25\% compared with the corresponding values determined by the TT or KPT methods.

Table 5. TCCs of the pastures in Wulan County under different precipitation scenarios, calculated by the three methods $\left(10^{4}\right.$ sheep units).

\begin{tabular}{|c|c|c|c|c|c|c|c|c|}
\hline \multirow{2}{*}{ Method } & \multicolumn{2}{|c|}{ Item } & \multicolumn{2}{|c|}{ Wet Year (2016) } & \multicolumn{3}{|c|}{ Normal Year } & \multirow{2}{*}{$\begin{array}{r}\text { Dry Year } \\
\text { Chaka } \\
\text { Basin }\end{array}$} \\
\hline & & & $\begin{array}{l}\text { Xisai } \\
\text { Basin }\end{array}$ & $\begin{array}{l}\text { Chaka } \\
\text { Basin }\end{array}$ & $\begin{array}{l}\text { Xisai } \\
\text { Basin }\end{array}$ & $\begin{array}{l}\text { Chaka } \\
\text { Basin }\end{array}$ & $\begin{array}{l}\text { Xisai } \\
\text { Basin }\end{array}$ & \\
\hline \multirow{5}{*}{$\begin{array}{l}\text { Traditional } \\
\text { theory (TT) }\end{array}$} & \multirow{2}{*}{$\begin{array}{l}\text { Carrying } \\
\text { capacity }\end{array}$} & Warm-season & 78.40 & 15.50 & 69.38 & 13.72 & 60.36 & 11.93 \\
\hline & & Cool-season & 77.24 & 15.88 & 68.71 & 14.18 & 60.17 & 12.48 \\
\hline & \multirow{3}{*}{ TCC } & Warm-season & 78.40 & 15.50 & 69.38 & 13.72 & 60.36 & 11.93 \\
\hline & & Cool-season & 77.24 & 15.88 & 68.71 & 14.18 & 60.17 & 12.48 \\
\hline & & Year-round & 77.70 & 15.73 & 68.97 & 14.00 & 60.25 & 12.26 \\
\hline \multirow{5}{*}{$\begin{array}{l}\text { Key pasture } \\
\text { theory }(\mathrm{KPT})\end{array}$} & \multirow{2}{*}{$\begin{array}{l}\text { Carrying } \\
\text { capacity }\end{array}$} & Warm-season & 78.40 & 15.50 & 69.38 & 13.72 & 60.36 & 11.93 \\
\hline & & Cool-season & 77.24 & 15.88 & 68.71 & 14.18 & 60.17 & 12.48 \\
\hline & \multirow{3}{*}{ TCC } & Warm-season & 77.24 & 15.50 & 68.71 & 13.72 & 60.17 & 11.93 \\
\hline & & Cool-season & 77.24 & 15.50 & 68.71 & 13.72 & 60.17 & 11.93 \\
\hline & & Year-round & 77.24 & 15.50 & 68.71 & 13.72 & 60.17 & 11.93 \\
\hline \multirow{5}{*}{$\begin{array}{c}\text { Dynamic key } \\
\text { pasture theory } \\
(\mathrm{DKPT})\end{array}$} & \multirow{2}{*}{$\begin{array}{l}\text { Carrying } \\
\text { capacity }\end{array}$} & $a^{\prime}$ & 83.97 & 16.60 & 74.31 & 14.69 & 64.65 & 12.78 \\
\hline & & $a^{\prime \prime}$ & 115.22 & 23.69 & 102.49 & 21.15 & 89.76 & 18.62 \\
\hline & \multirow{3}{*}{ TCC } & Warm-season & 83.97 & 16.60 & 74.31 & 14.69 & 64.65 & 12.78 \\
\hline & & Cool-season & 45.74 & 9.04 & 40.48 & 8.00 & 35.22 & 6.96 \\
\hline & & Year-round & 65.01 & 12.86 & 57.54 & 11.38 & 50.06 & 9.90 \\
\hline \multirow{6}{*}{$\begin{array}{l}\text { Deviation of } \\
\text { TCCs }(\%)\end{array}$} & \multirow{3}{*}{$\begin{array}{c}\text { DKPT vs. } \\
\text { TT }\end{array}$} & Warm-season & 7.10 & 7.10 & 7.11 & 7.07 & 7.11 & 7.12 \\
\hline & & Cool-season & -40.78 & -43.07 & -41.09 & -43.58 & -41.47 & -44.23 \\
\hline & & Year-round & -16.33 & -18.25 & -16.57 & -18.71 & -16.91 & -19.25 \\
\hline & \multirow{3}{*}{$\begin{array}{c}\text { DKPT vs. } \\
\text { KPT }\end{array}$} & Warm-season & 8.71 & 7.10 & 8.15 & 7.07 & 7.45 & 7.12 \\
\hline & & Cool-season & -40.78 & -41.68 & -41.09 & -41.69 & -41.47 & -41.66 \\
\hline & & Year-round & -15.83 & -17.03 & -16.26 & -17.06 & -16.80 & -17.02 \\
\hline
\end{tabular}

TCC is the theoretical carrying capacity; $a^{\prime}$ and $a^{\prime \prime}$ are the stocking numbers at midyear based on the carrying capacity of warm-season pastures and cool-season pastures, respectively. 


\subsection{Evaluation of the Forage-Livestock Balance in Representative Year Based on the DKPT Method}

The evaluation of the forage-livestock balance in the PWC in the representative year of 2016 was carried out with a combination of DKPT and the FLBI (Table 6). In the Xisai Basin, the warm-season pasture and the cool-season pasture were underloaded (FLBI $=-43.58 \%$ ) and balanced (FLBI $=-15.39 \%)$, respectively, and the whole-season pasture region was underloaded (FLBI $=-35.19 \%$ ). In the Chaka Basin, the states of the seasonal pasture region in the warm season, the cool season and the whole year were marginally overloaded $($ FLBI $=-13.07 \%)$, overloaded $($ FLBI $=56.75 \%$ ) and overloaded $(\mathrm{FLBI}=24.34 \%)$, respectively. Obviously, in the Xisai Basin, the grassland resources were not fully utilized, especially in the warm-season pasture, where it was necessary to increase the livestock number by about 365,900 (sheep units) to utilize the available grass production, whereas the slaughter rate had to be adjusted appropriately to control the livestock number within 457,400 (sheep units) on the cool-season pasture. In the Chaka Basin, overloading would lead to the degradation of the grasslands if it were not controlled in time, which would negatively affect the stability of the regional grassland ecosystem. As a consequence, it was necessary to reduce the livestock number in the warm-season pasture by approximately 21,700 (sheep units), and the slaughter rate had to be adjusted appropriately to keep the livestock number within 90,400 (sheep units) on the cool-season pasture. These evaluation results proved to be extremely useful for guiding the sustainable development of the PWC.

Table 6. Evaluation of forage-livestock balance based on DKPT and the FLBI in the representative year.

\begin{tabular}{|c|c|c|c|c|c|}
\hline District & Item & $\begin{array}{c}\text { TCC } \\
\left(10^{4} \text { Sheep Units) }\right.\end{array}$ & $\begin{array}{c}\text { ACC } \\
\left(10^{4} \text { Sheep Units) }\right.\end{array}$ & FLBI (\%) & $\begin{array}{l}\text { Evaluation } \\
\text { Result }\end{array}$ \\
\hline \multirow{3}{*}{ Xisai Basin } & Warm-season & 83.97 & 47.38 & -43.58 & Underloaded \\
\hline & Cool-season & 45.74 & 38.70 & -15.39 & Balanced \\
\hline & Year-round & 65.01 & 42.13 & -35.19 & Underloaded \\
\hline \multirow{3}{*}{ Chaka Basin } & Warm-season & 16.60 & 18.77 & 13.07 & $\begin{array}{l}\text { Marginally } \\
\text { overloaded }\end{array}$ \\
\hline & Cool-season & 9.04 & 14.17 & 56.75 & Overloaded \\
\hline & Year-round & 12.86 & 15.99 & 24.34 & Overloaded \\
\hline
\end{tabular}

DKPT refers to dynamic key pasture theory; FLBI represents the forage-livestock balance index; TCC and ACC are the theoretical carrying capacity and the actual carrying capacity, respectively.

\section{Discussion}

The analysis above provides quantitative support for reports that the evaluation of the forage-livestock balance in the alpine desert seasonal grazing regions on the basis of the TT or KPT methods does not fully take into consideration the unique features of the seasonal grazing regions in the alpine desert grasslands of China, such as the grass growth period, regional precipitation and the dynamic changes in livestock numbers as well as the natural relationship between forage supply and demand. As a consequence, the TCCs of the different seasonal pastures in the seasonal grazing regions have previously been calculated separately [30,31]. In general, grassland productivity has been shown to be positively correlated with regional precipitation conditions [32-34]. In the current study, the livestock number fell sharply in October owing to the slaughter of livestock, the slaughter rate reaching $40 \%$ to $60 \%$. If the ACC of the warm-season pasture was controlled by any index calculated using the TT or KPT methods, the ACC of the cool-season pasture would be much smaller than its corresponding TCC after grazing transferred to the cool-season pasture as a result of livestock slaughter, resulting in a major waste of pasture resources. On the contrary, if the ACC of the cool-season pasture were controlled, the warm-season pasture would be overloaded according to Equation (13). DKPT was based on the KPT method, but with further refining of the cycle division of forage supply and livestock demand and the introduction of the dynamic factors $\alpha$ and $\beta$. The TCC calculated by DKPT was in line with the natural dynamic rhythm of forage supply and livestock demand and, thus, had greater practical value and applicability than the TCC calculated by either TT or KPT. 
The results for the PWC calculated by DKPT reflected that the division of the areas into warm-season pastures and cool-season pastures was highly inappropriate. The area proportion of the cool-season pasture was too high, causing a major surplus of more than $50 \%$ when the livestock number of the warm-season pasture reached its TCC. Generally, cool-season pastures are mainly distributed in the wide valleys and basins at lower altitudes, with abundant water, suitable temperatures and high grass yields, and are suitable for grazing in the warm season as well. Therefore, part of the cool-season pasture could be allocated for grazing in the warm season to improve the division between warm-season and cool-season pastures. It is also recommended that rotational grazing be actively developed, using surplus pasture to develop artificial or mowing grasslands and increasing the utilization of grassland resources and the carrying capacity by enhancing the resistance to extreme weather. Additionally, the pastures in the two basins of Wulan County were in unbalanced states, and the ACCs in the warm-season and cool-season pastures were imbalanced. The slaughter rate $\alpha$ is the key factor in the DKPT method, reflecting the dynamic relationship between livestock numbers in the warm-season and cool-season pastures. For the PWC, $\alpha$ should be increased in the Xisai Basin and reduced in the Chaka Basin. Increasing the slaughter rate could, on the one hand, effectively increase the income of the herders and, on the other hand, reduce the carrying pressure on the cool-season pastures. However, too high a slaughter rate would lead to insufficient livestock numbers in the cool season, directly affecting breeding and the recovery of livestock numbers in the following year [27]. Therefore, the adjustment of the slaughter rate should be coordinated with the relative adjustment of the pasture areas to ensure a reasonable livestock number at year's end, a reasonable proportion of females, etc.

\section{Conclusions}

For the seasonal grazing regions in the alpine desert grasslands of China, the grassland productivity and TCCs of pastures were significantly affected by the phonological period and regional precipitation as well as the dynamic changes in livestock numbers. The natural processes of forage supply and livestock demand were markedly uncoordinated and formed a dynamic cycle with four subprocesses. The DKPT method proved to be an improvement on the KPT method by introducing two dynamic factors, $\alpha$ and $\beta$, and fully considering the natural relationship between grassland supply and livestock demand in seasonal grazing regions in alpine desert grasslands of China. As a consequence, the evaluation of the forage-livestock balance based on DKPT had greater applicability and relevance than that achieved by either the TT or KPT methods.

The PWC are representative of the seasonal grazing regions in alpine desert grasslands of China. The TCC estimates and the results of the evaluation of the forage-livestock balance in the PWC based on the DKPT method indicated that the proportion of the cool-season pastures was too high, resulting in a huge surplus of more than $50 \%$. The state of the forage-livestock balance in the Xisai Basin was underloaded on the whole, whereas it was underloaded in the warm-season pasture by up to $43.58 \%$. The state of the forage-livestock balance in the Chaka Basin was overloaded overall, with the rate of overloading in the cool-season pasture being up to $56.75 \%$. According to this analysis, some guidelines for regulation measures have been proposed, such as altered pasture division, ACC control, slaughter rate adjustment, the development of rotational grazing, the coupling of natural and artificial grasslands and so on, providing reference materials for the sustainable development of the economy, society and ecoenvironment of Wulan County.

Author Contributions: All the authors contributed significantly to this study. H.L. and X.S. proposed the idea and wrote the manuscript. L.Q. and W.W. collected and organized the data. H.L., X.L., Z.H. and Y.L. processed the data. All authors have read and agreed to the published version of the manuscript.

Funding: This research was funded by the National Key Research and Development Program of China, grant number 2016YFC0400301.

Conflicts of Interest: The authors declare no conflict of interest. 


\section{References}

1. Ebrahimi, M.; Khosravi, H.; Rigi, M. Short-term grazing exclusion from heavy livestock rangelands affects vegetation cover and soil properties in natural ecosystems of southeastern Iran. Ecol. Eng. 2016, 95, 10-18. [CrossRef]

2. Harrison, P.A.; Vandewalle, M.; Sykes, M.T.; Berry, P.M.; Bugter, R.; de Bello, F.; Feld, C.K.; Grandin, U.; Harrington, R.; Haslett, J.R.; et al. Identifying and prioritising services in European terrestrial and freshwater ecosystems. Biodivers. Conserv. 2010, 19, 2791-2821. [CrossRef]

3. Smith, P. Do grasslands act as a perpetual sink for carbon? Glob. Chang. Biol. 2014, 20, 2708-2711. [CrossRef] [PubMed]

4. Ryals, R.; Hartman, M.D.; Parton, W.J.; DeLonge, M.S.; Silver, W.L. Long-term climate change mitigation potential with organic matter management on grasslands. Ecol. Appl. 2015, 25, 531-545. [CrossRef]

5. Lu, H.; Li, H.; Gao, Z.; Wang, D.; Wang, J. Water and land resources allocation model of pastoral area based on grassland ecological conservation. Nongye Gongcheng Xuebao Trans. Chin. Soc. Agric. Eng. 2016, 32, 123-130. [CrossRef]

6. Zhou, H.; Zhao, X.; Tang, Y.; Gu, S.; Zhou, L. Alpine grassland degradation and its control in the source region of the Yangtze and Yellow Rivers, China. Grassl. Sci. 2005, 51, 191-203. [CrossRef]

7. Ramankutty, N.; Evan, A.T.; Monfreda, C.; Foley, J.A. Farming the planet: 1. Geographic distribution of global agricultural lands in the year 2000. Glob. Biogeochem. Cycles 2008, 22. [CrossRef]

8. Yang, F.; Shao, Q.; Guo, X.; Tang, Y.; Li, Y.; Wang, D.; Wang, Y.; Fan, J. Effect of large wild herbivore populations on the forage-livestock balance in the source region of the Yellow River. Sustainability 2018, 10, 340. [CrossRef]

9. Cao, Y.; Wu, J.; Zhang, X.; Niu, B.; Li, M.; Zhang, Y.; Wang, X.; Wang, Z. Dynamic forage-livestock balance analysis in alpine grasslands on the Northern Tibetan Plateau. J. Environ. Manag. 2019, 238, 352-359. [CrossRef]

10. Bai, Y.; Pan, Q.; Xing, Q. Fundamental theories and technologies for optimizing the production functions and ecological functions in grassland ecosystems. Kexue Tongbao Chin. Sci. Bull. 2016, 61, 201-212. [CrossRef]

11. Shang, Z.H.; Gibb, M.J.; Leiber, F.; Ismail, M.; Ding, L.M.; Guo, X.S.; Long, R.J. The sustainable development of grassland-livestock systems on the Tibetan plateau: Problems, strategies and prospects. Rangel. J. 2014, 36, 267-296. [CrossRef]

12. Jia, Y. On the concepts and practices concerning grassland-livestock balance. Acta Agrestia Sin. 2005, 13, 265-268. [CrossRef]

13. Li, M.; Li, Z.; Bao, Y.; Zhang, J.; Liu, L.; Li, Z. The study on grassland carrying capacity and regulatory approaches of livestock-feeds balance in Hulunbuir grassland. Chin. J. Grassl. 2016, 38, 72-78. [CrossRef]

14. Ma, Q.; Chai, L.; Hou, F.; Chang, S.; Ma, Y.; Tsunekawa, A.; Cheng, Y. Quantifying grazing intensity using remote sensing in alpine meadows on Qinghai-Tibetan Plateau. Sustainability 2019, 11, 417. [CrossRef]

15. Zhang, B.; Zhang, L.; Xie, D.; Yin, X.; Liu, C.; Liu, G. Application of synthetic NDVI time series blended from landsat and MODIS data for grassland biomass estimation. Remote Sens. 2016, 8, 10. [CrossRef]

16. Qin, X.; Hong, J.; Ma, X.; Wang, X. Global patterns in above-ground net primary production and precipitation-use efficiency in grasslands. J. Mt. Sci. 2018, 15, 1682-1692. [CrossRef]

17. Jia, W.; Liu, M.; Yang, Y.; He, H.; Zhu, X.; Yang, F.; Yin, C.; Xiang, W. Estimation and uncertainty analyses of grassland biomass in Northern China: Comparison of multiple remote sensing data sources and modeling approaches. Ecol. Indic. 2016, 60, 1031-1040. [CrossRef]

18. Ministry of Agriculture of the People's Republic of China. Calculation of Rangeland Carrying Capacity, NY/T 635-2015; Ministry of Agriculture of the People's Republic of China: Beijing, China, 2015.

19. Li, Q. Series studies of animal demanding-feed availability balance control (2)—Evaluation on current method of animal carrying capacity calculation. Pratacult. Sci. 2011, 28, 2042-2045.

20. Xu, M. A review of grassland carrying capacity: Perspective and dilemma for research in China on "forage-livestock balance". Acta Pratacult. Sin. 2014, 23, 321-329. [CrossRef]

21. Chen, Q. Key pasture, seasonal grazing and sustainable development of grassland animal husbandry production in China. Acta Pratacult. Sin. 2005, 29-34. [CrossRef]

22. Local Chronicles of Wulan County, Qinghai Province, China; San Qin Press: Xi'an, China, 2003. 
23. Li, X.Q.; Li, X.M. Trend of degenerated grassland in Haixi Prefecture Qinghai Province. Qinghai Pratacult. 2018, 27, 37-41. [CrossRef]

24. Yang, F. Study of Feed Balance in Qilian Mountain Pastoral Areas and Precision Management of Sheep. Master's Thesis, Gansu Agricultural University, Lanzhou, China, 2012.

25. Fei, Y.X.; Chao, Y.F. Dynamic analysis of natural grassland resources during the years of Haixi Prefecture. Qinghai Pratacult. 2018, 27, 41-44, 48. [CrossRef]

26. Xu, B.; Yang, X.C.; Jin, Y.X.; Wang, D.L.; Yang, Z.; Li, J.Y.; Liu, H.Q.; Yu, H.D.; Ma, H.L. Monitoring and evaluation of grassland-livestock balance in pastoral and semi-pastoral counties of China. Geogr. Res. 2012, 31, 1998-2006.

27. Qin, L.; Song, X.; Feng, X. Forage-livestock dynamic balance of pasturing area based on rotational grazing theory in northern slope of Qilian Mountains. Nongye Gongcheng Xuebao Trans. Chin. Soc. Agric. Eng. 2019, 35, 256-264. [CrossRef]

28. Yu, L.; Zhou, L.; Liu, W.; Zhou, H.K. Using Remote Sensing and GIS Technologies to Estimate Grass Yield and Livestock Carrying Capacity of Alpine Grasslands in Golog Prefecture, China. Pedosphere 2010, 20, 342-351. [CrossRef]

29. Yu, M.; Ellis, J.E.; Epstein, H.E. Regional Analysis of Climate, Primary Production, and Livestock Density in Inner Mongolia. J. Environ. Qual. 2004, 33, 1675-1681. [CrossRef]

30. Sun, J.; Jiao, T.; Li, Y.; Wang, F.; Wang, P.; Yu, X. A Study on the Optimal Allocation of the Alpine Pasture Grassland-Livestock-A Case of a Herder in Maqin County, Qinghai Province. Acta Agrestia Sin. 2019, 27, 728-735. [CrossRef]

31. Hao, L.; Han, X.; Niu, J.; Zhang, X.; Xiang, Y.; Wang, X.; Chai, S.; Long, R.; Liu, S. Study on Nutrient Balance of Grassland in Henan County, Sanjiang. Acta Agrestia Sin. 2018, 26, 520-524. [CrossRef]

32. Petrie, M.D.; Peters, D.P.C.; Yao, J.; Blair, J.M.; Burruss, N.D.; Collins, S.L.; Derner, J.D.; Gherardi, L.A.; Hendrickson, J.R.; Sala, O.E.; et al. Regional grassland productivity responses to precipitation during multiyear above- and below-average rainfall periods. Glob. Chang. Biol. 2018, 24, 1935-1951. [CrossRef]

33. Power, S.A.; Barnett, K.L.; Ochoa-Hueso, R.; Facey, S.L.; Gibson-Forty, E.V.J.; Hartley, S.E.; Nielsen, U.N.; Tissue, D.T.; Johnson, S.N. DRI-Grass: A new experimental platform for addressing grassland ecosystem responses to future precipitation scenarios in South-East Australia. Front. Plant Sci. 2016, 7, 1373. [CrossRef]

34. Brookshire, E.N.J.; Weaver, T. Long-term decline in grassland productivity driven by increasing dryness. Nat. Commun. 2015, 6, 7148. [CrossRef] [PubMed] 